\title{
SEMEADURA DA SOJA NO PERÍODO DE SAFRINHA: POTENCIAL FISIOLÓGICO E SANIDADE DAS SEMENTES ${ }^{1}$
}

\author{
ALESSANDRO DE LUCCA E BRACCINI², IVO DE SÁ MOTTA³, CARLOS ALBERTO SCAPIM², \\ MARIA DO CARMO LANA BRACCINI ${ }^{4}$, MARIZANGELA RIZZATTI ÁVILA ${ }^{3}$, SANDRA REGINA PELEGRINELLO SCHUAB ${ }^{5}$
}

\begin{abstract}
RESUMO - O presente trabalho foi conduzido com objetivo de avaliar o efeito da semeadura, na época de "safrinha”, sobre o potencial fisiológico e a sanidade das sementes de cinco cultivares de soja (Glycine max (L.) Merrill). Para tanto, foram conduzidos três ensaios, em dois anos agrícolas (1998/99 e 1999/00), com delineamento em blocos completos casualizados, instalando-se um ensaio em cada época de semeadura (15/11, 15/01 e 15/02). Os cultivares estudados foram BRS 132, BRS 133, BRS 134, BR 16 e FT-Estrela. As sementes foram avaliadas por meio dos testes de germinação e de vigor (primeira contagem, classificação do vigor das plântulas, envelhecimento acelerado, comprimento das plântulas e biomassa seca das plântulas), qualidade visual e da sanidade. As sementes produzidas no período de safrinha apresentaram potencial fisiológico e sanidade inferiores aos verificados quando a semeadura foi realizada em novembro, embora a semeadura realizada em fevereiro tenha proporcionado a obtenção de sementes com qualidade satisfatória. No entanto, a semeadura efetuada no mês de janeiro não foi adequada à produção de sementes de boa qualidade. $\mathrm{O}$ atraso na época de semeadura e promove variações nas respostas dos cultivares quanto ao potencial fisiológico das sementes.
\end{abstract}

Termos para indexação: soja, sementes, época de semeadura, germinação, vigor, patógenos.

\section{SOYBEAN DELAYED SOWING DATE: SEED HEALTH AND SEED PHYSIOLOGICAL POTENTIAL}

\begin{abstract}
The present study was accomplished with the objective of evaluating the influence of delayed sowing dates on seed health and seed physiological potential of five soybean cultivars. It was conducted a five cultivar assay sown on different dates (11/15, 01/15 and 02/15) in two experimental years (1998/99 and 1999/00), in a randomized complete block design. Each assay was sown on different dates. The evaluated cultivars were BRS 132, BRS 133, BRS 134, BR 16 and FT-Estrela, of different maturation groups. Seeds produced on the different sowing dates were evaluated by germination, first count, accelerated aging, seedling vigor classification, seedling length and dry biomass tests, visual seed evaluation and seed health. The seeds produced on the delayed sowing dates showed lower physiological potential compared to those from the November sowing date although seeds from the February sowing date showed satisfactory quality level. It was also concluded that delayed sowing emphasizes differences in seed physiological potential among cultivars.
\end{abstract}

Index terms: soybean, seeds, sowing date, germination, vigor, pathogens.

\footnotetext{
${ }^{1}$ Aceito para publicação em 12.06.2003.

2 Eng $^{\circ}$ Agr $^{\circ}$, D.S., Prof. Adjunto do Depto. de Agronomia da Universidade Estadual de Maringá (UEM); Av. Colombo, 5790, 87020-900, Maringá, PR; bolsista do CNPq; e-mail: albraccini@uol.com.br

${ }^{3}$ Eng $^{\circ}$ Agr $^{\circ}$, Estudante do Programa de Pós-Graduação em Agronomia da Universidade Estadual de Maringá (UEM).
}

\footnotetext{
${ }^{4}$ Engo ${ }^{\text {Agro }}$, D.S., Prof. Adjunto do Centro de Ciências Agrárias da Universidade Estadual do Oeste do Paraná (UNIOESTE); Rua Pernambuco, 1777, 85960-000, Marechal Cândido Rondon, PR.

${ }^{5}$ Bióloga, M.Sc., Estudante do Programa de Pós-Graduação em Agronomia da Universidade Estadual de Maringá (UEM).
} 


\section{INTRODUÇÃO}

A cultura da soja é uma das mais importantes no Brasil, em função de seu grande valor sócio-econômico, determinado pelas inúmeras aplicações de seus produtos e subprodutos e expressão no mercado interno e exportação. No contexto mundial de produção de soja, o Brasil ocupa a segunda colocação, sendo superado apenas pelos Estados Unidos, em termos de área cultivada e de produção total. Por esses motivos recebe intensa atenção da pesquisa, principalmente para a obtenção de informações que possibilitem aumentos na produtividade. Para a obtenção de maiores rendimentos por área, é indispensável, além de técnicas adequadas de cultivo, a utilização de sementes de alta qualidade, expressa pelos componentes genético, físico, fisiológico e sanitário.

O desenvolvimento das plantas de soja é influenciado por diversos fatores ambientais, como temperatura, precipitação pluvial, umidade relativa do ar, umidade do solo e fotoperíodo. Considerando as variações desses fatores durante o ano e as respostas da soja, nenhum outro fator cultural isolado influencia tanto o desenvolvimento e a produção da soja quanto a época de semeadura (Rocha et al., 1984; Marcos Filho, 1986; Bhéring et al., 1991).

Por outro lado, a literatura relata que o período de permanência das sementes de soja no campo, após a maturidade fisiológica, é fator importante na deterioração e, portanto, determina queda do vigor. Segundo Green et al. (1965), condições ambientais adversas, no período de maturação, constituem fatores prejudiciais à obtenção de sementes de boa qualidade. Segundo esses mesmos autores, sementes de soja oriundas de cultivares tardios geralmente atingem a maturidade após o período de clima quente e seco e exibem maior vigor que as sementes originadas de cultivares precoces, cuja maturação ocorre em épocas quentes e úmidas. Desta forma, torna-se evidente que o emprego de cultivares com alta qualidade de sementes, associado à escolha de regiões com características climáticas favoráveis, e ao escalonamento da época de semeadura, podem, seguramente, proporcionar a produção de sementes de melhor qualidade, além de melhores rendimentos na exploração comercial da cultura.

É reconhecido que o máximo potencial fisiológico das sementes de soja é alcançado por ocasião da maturidade, coincidindo com o máximo acúmulo de matéria seca (Jacinto \& Carvalho, 1974; Marcos Filho, 1979; Popinigis, 1985). Por outro lado, o processo de deterioração inicia-se nessa época, agravando-se quando o grau de umidade das sementes de- cresce até atingir níveis inferiores a 25\% (Harrington, 1973; Mondragon \& Potts, 1974).

A deterioração pode ser definida como um processo que envolve mudanças citológicas, bioquímicas, fisiológicas e físicas que conduzem à morte das sementes. O processo deteriorativo das sementes é a principal causa do prejuízo à sua viabilidade e vigor, podendo influenciar o rendimento de uma cultura pelo decréscimo na germinação, estabelecendo uma população subótima de plantas por unidade de área e resultando em menor desempenho das plantas sobreviventes (Roberts, 1974). O processo de deterioração tem sido caracterizado por Delouche (1982) como inexorável e irreversível, mínimo na época da maturidade fisiológica e variável entre lotes de sementes da mesma espécie e cultivar.

Segundo TeKrony et al. (1980), a intensidade de redução da germinação e do vigor das sementes varia de acordo com a época de semeadura e com as condições de temperatura, umidade relativa e precipitações pluviais durante as fases de maturação e colheita. Com base nesses estudos, os autores sugerem que a utilização de cultivares de ciclo tardio e a prática de retardamento da semeadura da soja podem submeter as plantas a regime climático mais propício para a produção de sementes de alta qualidade. Neste contexto, Vieira et al. (1982) constataram que temperaturas amenas favorecem a qualidade da semente e que condições quentes e úmidas, com excesso de precipitações pluviais, poderão comprometer severamente a germinação e o vigor das sementes.

Outro problema que pode provocar graves prejuízos à qualidade das sementes de soja, refere-se às lesões causadas pelo ataque intenso de percevejos (Costa et al., 1995). Em geral, o ataque de insetos sugadores concentra-se no final do ciclo da cultura. Portanto, o escalonamento da época de semeadura pode ter reflexos positivos ou negativos sobre a incidência das injúrias provocadas pelo ataque de percevejos, intimamente relacionadas à escolha da região produtora e das suas condições climáticas predominantes.

Em virtude dos preços relativamente baixos atingidos durante a comercialização das principais culturas de inverno, principalmente do trigo, bem como da carência de outras opções de cultivo, vários produtores têm buscado alternativas para obter melhor rendimento econômico no período de entressafra ou safrinha. Uma das opções é representada pelo cultivo do milho após a colheita da soja. Algumas regiões do estado do Paraná têm optado, também, pelo cultivo da soja após o período normal de safra. Contudo, as informações disponíveis na literatura a respeito da semeadura da soja no período de safrinha são escassas, não permitindo o esclareci- 
mento desejável do assunto, além de dificultar recomendações mais específicas para essa situação.

Desta forma, objetivou-se, neste trabalho, avaliar o potencial fisiológico e a sanidade das sementes provenientes de cinco cultivares de soja, em dois anos agrícolas, sob influência da semeadura realizada no período de safrinha.

\section{MATERIAL E MÉTODOS}

O presente trabalho foi conduzido em área experimental localizada no Centro Técnico de Irrigação (CTI), pertencente ao Departamento de Agronomia da Universidade Estadual de Maringá (DAG/UEM), utilizando sementes de cin- co cultivares de soja. Os dados de precipitação pluvial, temperaturas máxima e mínima diárias e umidade relativa do ar, referentes aos períodos de duração dos ensaios, nos anos agrícolas de 1998/99 e 1999/00, foram coletados durante todo o período de condução da cultura e estão apresentados na Figura 1.

Foram instalados três ensaios, em dois anos agrícolas (1998/99 e 1999/00), com cinco tratamentos e três repetições, em delineamento blocos completos casualizados, instalandose um ensaio em cada época de semeadura (15/11, 15/01 e 15/02). O plantio na época preferencial (15/11) foi utilizado como padrão, na comparação com as demais épocas de semeadura. Os cultivares estudados foram os seguintes: BRS
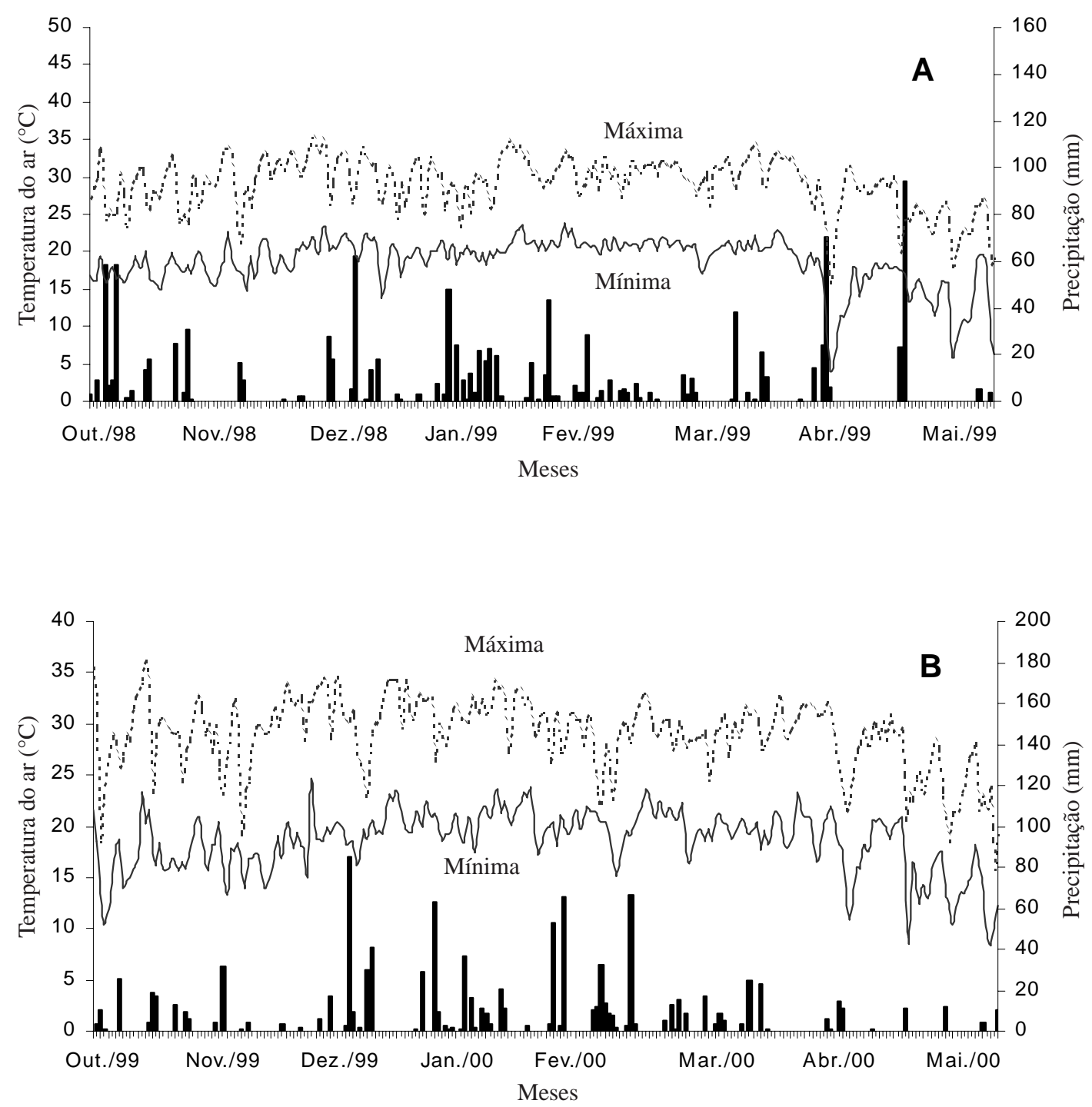

FIG. 1. Precipitação pluvial e temperaturas máxima e mínima diárias, observadas no decorrer da fase experimental, em 1998/99 (A) e 1999/00 (B). 
132 (precoce), BRS 133 (semiprecoce), BR 16 (semiprecoce), BRS 134 (médio) e FT-Estrela (tardio).

As parcelas foram representadas por quatro linhas de 5 metros de comprimento, espaçadas de $0,5 \mathrm{~m}$ entre si. $\mathrm{Na}$ colheita foram eliminadas as duas linhas externas, bem como $0,5 \mathrm{~m}$ de cada extremidade das linhas centrais, constituindo bordaduras. A área útil das parcelas foi de quatro metros quadrados.

O preparo do solo, a adubação e as demais práticas culturais foram as mesmas preconizadas pelo sistema de produção da região. O solo da área experimental foi analisado quanto às características químicas e a adubação realizada de acordo com as recomendações da análise de solo (Embrapa Soja, 1999).

Para a semeadura, foram utilizadas 30 a 35 sementes por metro de fileira. Duas semanas após a emergência das plântulas, foram realizados desbastes, deixando-se cerca de 20 plantas por metro linear. As plantas daninhas foram controladas por meio de aplicação de herbicidas e capinas manuais e o controle de lagartas, percevejos e outros insetos foi realizado, sempre que necessário, mediante pulverizações sistemáticas de inseticidas recomendados para cada espécie de inseto, até o final do ciclo da cultura.

As plantas foram colhidas manualmente, cinco a oito dias após o estádio $\mathrm{R}_{8}$ de desenvolvimento, ou seja, quando $95 \%$ das vagens apresentavam a coloração típica de vagem madura (Fehr et al., 1971). Após a colheita, as vagens foram debulhadas em máquina trilhadeira estacionária e, as sementes, limpas com o auxílio de peneiras, secadas em condições naturais e acondicionadas em sacos de papel; em seguida foram mantidas em câmara fria, a $10^{\circ} \mathrm{C}$ e $50 \%$ de umidade relativa do ar, até o final da colheita e início das avaliações de laboratório.

No Laboratório de Tecnologia de Sementes do Núcleo de Pesquisas Aplicadas à Agricultura (NUPAGRI), foram realizados os seguintes testes: germinação, primeira contagem, envelhecimento acelerado, comprimento das plântulas, biomassa seca das plântulas e classificação do vigor das plântulas; efetuou-se, também, a avaliação visual das sementes e o teste de sanidade.

Teste de germinação - conduzido com quatro subamostras de 50 sementes para cada tratamento e repetição, colocadas para germinar entre três folhas de papel-toalha, umedecidas com água desmineralizada, na proporção de três vezes o peso do papel seco. Foram confeccionados rolos, levados para germinador regulado para manter temperatura constante de $25 \pm 1^{\circ} \mathrm{C}$. As avaliações foram realizadas aos cinco e oito dias após a semeadura, computando-se a porcenta- gem de plântulas normais, segundo os critérios estabelecidos pelas Regras para Análise de Sementes (Brasil, 1992). A primeira contagem foi considerada um indicativo do vigor e a contagem final, da viabilidade das sementes.

Envelhecimento acelerado - realizado com quatro subamostras de 50 sementes para cada tratamento e repetição de campo, distribuídas sobre uma tela fixada no interior de caixas plásticas (tipo "gerbox"). No interior de cada caixa foram adicionados $40 \mathrm{~mL}$ de água destilada para formar uma câmara úmida. Em seguida, as caixas foram fechadas, lacradas com fita crepe e mantidas em incubadora do tipo B.O.D., a $41^{\circ} \mathrm{C}$, durante 48 horas, conforme as recomendações de Marcos Filho (1999). Após o período de envelhecimento, as sementes foram submetidas ao teste padrão de germinação, conforme descrito anteriormente, e a avaliação realizada no quinto dia após a semeadura.

Comprimento das plântulas - foram utilizadas cinco subamostras de 20 sementes para cada tratamento e repetição, colocadas para germinar entre três folhas de papel-toalha. As sementes foram distribuídas manualmente no sentido longitudinal das folhas, com o hilo voltado para a parte inferior do papel. Em seguida, foram confeccionados rolos, sendo estes colocados em sacos plásticos de coloração preta, com as finalidades de manter constante a umidade no seu interior e de eliminar o efeito da luminosidade. Os rolos foram distribuídos na posição vertical em germinador regulado a $25 \pm 1^{\circ} \mathrm{C}$, durante sete dias. A avaliação foi realizada apenas nas plântulas normais, eliminando-se as anormais e sementes mortas, efetuando-se as medições em centímetros (Nakagawa, 1999).

Biomassa seca das plântulas - determinada em conjunto com o comprimento das plântulas, removendo-se os cotilédones. Os eixos embrionários de cada repetição foram colocados em sacos de papel e levados para secar em estufa com circulação de ar forçada, regulada a $80 \pm 2^{\circ} \mathrm{C}$, durante 24 horas. Após esse período, as amostras foram colocadas para resfriar em dessecadores e pesadas em balança analítica (0,001g). Os resultados foram expressos em mg/plântula (Nakagawa, 1999).

Classificação do vigor das plântulas - efetuada em conjunto com o teste de germinação, utilizando quatro repetições de 50 sementes. Por ocasião da avaliação do teste, as plântulas normais foram classificadas em fortes e fracas, segundo os critérios estabelecidos por Nakagawa (1999).

Avaliação visual das sementes - para avaliação dessa característica, realizada com base no aspecto geral de cada amostra, foram considerados, em conjunto, o grau de desenvolvimento das sementes, o enrugamento, a rachadura, a cor e o brilho do tegumento, a presença ou não de mancha púrpu- 
ra e lesões causadas por percevejos, atribuindo-se notas de 1 (muito boa) a 5 (muito ruim), considerando a parte fracionária.

Teste de sanidade - conduzido por meio do método do papel-filtro ou "blotter test", com 100 sementes divididas em quatro subamostras de 25 para cada tratamento e repetição colocadas em caixas plásticas (tipo “gerbox”), sobre quatro folhas de papel-filtro esterilizadas e umedecidas com água destilada e autoclavada. A incubação foi realizada em condição ambiente de laboratório, a $25^{\circ} \mathrm{C}$, em regime de 12 horas de iluminação com lâmpadas fluorescentes, alternadas com 12 horas de escuro, durante sete dias. Após esse período, procedeu-se a avaliação dos fungos presentes nas sementes, com o auxílio de microscópio estereoscópico e microscópio composto (Henning, 1994; Goulart, 1997).

O delineamento experimental utilizado foi em blocos casualizados com três repetições, sendo que cada época de semeadura foi constituída de ensaio individual de competição de cultivares. Posteriormente, os dados coletados foram submetidos a análise da variância conjunta e, na presença de interação significativa, procederam-se os desdobramentos necessários; as médias foram comparadas pelo teste de agrupamento de Scott-Knott (1974) para avaliação dos efeitos de cultivares e de épocas de semeadura $(p<0,05)$. A análise conjunta dos dados foi realizada para as três épocas de semeadura e dois anos agrícolas, uma vez que a razão entre o maior e o menor quadrado médio residual não foi superior a sete (Banzatto \& Kronka, 1995) para a maioria das características avaliadas, com exceção da biomassa seca e teste de sanidade. Para o teste de sanidade, no segundo ano agrícola, optou-se pela estatística descritiva, em razão das pressuposições básicas da análise de variância não serem atendidas, como a homogeneidade de variâncias.

\section{RESULTADOS E DISCUSSÃO}

Os dados climáticos de temperatura mínima, máxima e precipitação pluvial diária, coletados durante a condução dos ensaios, nos dois anos agrícolas, encontram-se ilustrados na Figura 1. A umidade relativa manteve-se relativamente alta, com mínima de 62,33\% e máxima de $86,66 \%$ no primeiro ano (1998/99) e, no segundo ano (1999/00), com umidade relativa do ar mínima de 46,33\% e máxima de 83,00, oscilando diariamente. A temperatura média do ar oscilou entre 19,4 e $26,0^{\circ} \mathrm{C}$ no ano agrícola de 1998/99, com temperatura máxima de $35,3^{\circ} \mathrm{C}$ registrada no mês de novembro e mínima de $4^{\circ} \mathrm{C}$ em abril. No segundo ano agrícola (1999/00), a temperatura média do ar oscilou entre 19,6 e $25,8^{\circ} \mathrm{C}$, enquanto que a temperatura máxima registrada foi de $36,2^{\circ} \mathrm{C}$ (outubro) e a mínima de $8,4^{\circ} \mathrm{C}$ (maio). Segundo Costa et al. (1987), os ambientes mais favoráveis à produção de sementes de soja de melhor qualidade fisiológica são aqueles com temperatura média inferior a $22^{\circ} \mathrm{C}$.

A ocorrência de precipitação foi relativamente alta durante o período de execução do experimento, com média de 140 mm mensais no ano agrícola de 1998/99 e de 131 mm em 1999/00, com exceção do mês de novembro no primeiro ano agrícola (30,9 mm) e dos meses de novembro, abril e maio no segundo ano agrícola, em que a precipitação média mensal foi de $40,7 \mathrm{~mm}$, acentuadamente inferior às registradas nos outros meses. O mês de novembro, em que foi realizada a primeira época de semeadura, apresentou baixa precipitação pluvial, sendo registrados apenas 30,9 e 52,4 mm, respectivamente para o primeiro e segundo anos agrícolas. As precipitações mais elevadas foram registradas no mês de outubro do ano agrícola de 1998/99, com 241,6 mm e no mês de dezembro do ano agrícola de 1999/00, com 280,9 mm de chuva.

Dentre as condições climáticas avaliadas, a alta umidade relativa oscilante e as elevadas temperaturas registradas no período foram consideradas desfavoráveis à manutenção da qualidade das sementes. A infecção das sementes de soja por Phomopsis sp. apresentou maior dependência da umidade relativa do que da temperatura média, em Lexington, EUA (TeKrony et al., 1984). Esse patógeno tem sido citado na literatura como sendo um dos principais causadores de deterioração, dentre os fungos que comprometem a qualidade das sementes de soja (Dhingra \& Acuña, 1997).

Na Tabela 1 são apresentados os resultados do desdobramento da interação entre cultivares e épocas de semeadura, dentro de cada ano agrícola, referentes às duas contagens do teste de germinação. Observa-se grande variabilidade no comportamento dos cultivares de soja, em relação à qualidade das sementes, nas diferentes épocas de semeadura e anos agrícolas avaliados. As sementes do cultivar BR 16 apresentaram menor potencial fisiológico na maioria das épocas de semeadura avaliadas, nos dois anos agrícolas. No primeiro ano agrícola, a semeadura realizada no mês de janeiro foi mais prejudicial à obtenção de sementes de melhor qualidade que as demais épocas de semeadura, para a maioria dos cultivares avaliados, com exceção do cultivar FT Estrela que não apresentou diferença significativa entre as épocas de semeadura. No segundo ano agrícola, praticamente não houve diferença significativa entre as épocas de semeadura para todos os cultivares, com exceção da BRS 132, na primeira 
TABELA 1. Médias estimadas da porcentagem de plântulas normais na primeira contagem (A) e na contagem final (B) do teste de germinação das sementes de cinco cultivares de soja, em três épocas de semeadura e dois anos experimentais (Maringá - PR).

\begin{tabular}{|c|c|c|c|c|c|c|c|c|}
\hline \multirow{3}{*}{ Cultivar } & \multicolumn{3}{|c|}{ Ano agrícola 1998/99 } & \multirow{3}{*}{ Média } & \multirow{2}{*}{\multicolumn{3}{|c|}{$\begin{array}{c}\text { Ano agrícola 1999/00 } \\
\text { Época de semeadura }\end{array}$}} & \multirow{3}{*}{$\begin{array}{c}\text { A } \\
\text { Média }\end{array}$} \\
\hline & \multicolumn{3}{|c|}{ Época de semeadura } & & & & & \\
\hline & $15 / 11$ & $15 / 01$ & $15 / 02$ & & $15 / 11$ & $15 / 01$ & $15 / 02$ & \\
\hline BRS 132 & $83 \mathrm{Aa}^{1}$ & $63 \mathrm{C} \mathrm{b}$ & $71 \mathrm{~B} \quad \mathrm{c}$ & 73 & $81 \mathrm{Ba}$ & $87 \mathrm{Aa}$ & $80 \mathrm{Ba}$ & 83 \\
\hline BRS 133 & $80 \mathrm{~A} \mathrm{~b}$ & $75 \mathrm{Ba}$ & $81 \mathrm{Aa}$ & 79 & $85 \mathrm{Aa}$ & $87 \mathrm{Aa}$ & $85 \mathrm{Aa}$ & 85 \\
\hline BRS 134 & 86Аа & $66 \mathrm{C} \mathrm{b}$ & $81 \mathrm{Ba}$ & 77 & 85Aa & 88Aa & 88Aa & 87 \\
\hline BR 16 & $80 \mathrm{~A} \mathrm{~b}$ & $56 \mathrm{~B} \quad \mathrm{C}$ & $76 \mathrm{~A} \mathrm{~b}$ & 71 & $75 \mathrm{~A} \mathrm{~b}$ & $78 \mathrm{~A} \mathrm{~b}$ & $77 \mathrm{~A} \mathrm{~b}$ & 76 \\
\hline FT-Estrela & $77 \mathrm{~A} \mathrm{~b}$ & $77 \mathrm{Aa}$ & $81 \mathrm{Aa}$ & 78 & 83Аа & 84Aa & $82 \mathrm{Aa}$ & 83 \\
\hline Média & 81 & 67 & 78 & & 82 & 85 & 82 & \\
\hline \multirow[t]{2}{*}{ CV (\%) } & \multicolumn{7}{|c|}{3,66} & \\
\hline & \multicolumn{3}{|c|}{ Ano agrícola 1998/99 } & & \multicolumn{3}{|c|}{ Ano agrícola 1999/00 } & B \\
\hline \multirow[t]{2}{*}{ Cultivar } & \multicolumn{3}{|c|}{ Época de semeadura } & Média & \multicolumn{3}{|c|}{ Época de semeadura } & Média \\
\hline & $15 / 11$ & $15 / 01$ & $15 / 02$ & & $15 / 11$ & $15 / 01$ & $15 / 02$ & \\
\hline BRS 132 & $90 \mathrm{Aa}$ & $67 \mathrm{C} \mathrm{b}$ & $75 B \quad b$ & 77 & $90 \mathrm{~A} \mathrm{~b}$ & $91 \mathrm{Aa}$ & $90 \mathrm{~A} \mathrm{~b}$ & 90 \\
\hline BRS 133 & $84 \mathrm{~A} \mathrm{~b}$ & $78 \mathrm{Ba}$ & 83Аа & 82 & $93 \mathrm{Aa}$ & $91 \mathrm{Aa}$ & $95 \mathrm{Aa}$ & 93 \\
\hline BRS 134 & $90 \mathrm{Aa}$ & $69 \mathrm{C} \mathrm{b}$ & $84 \mathrm{Ba}$ & 81 & 93Аа & $92 \mathrm{Aa}$ & 96Аа & 94 \\
\hline BR 16 & 89Аа & $59 \mathrm{C} \quad \mathrm{c}$ & $79 B \quad b$ & 76 & $87 \mathrm{~A} \quad \mathrm{~b}$ & $81 \mathrm{~B} \mathrm{~b}$ & $88 \mathrm{~A} \mathrm{~b}$ & 85 \\
\hline FT-Estrela & $82 \mathrm{~A} \mathrm{~b}$ & $80 \mathrm{Aa}$ & 84Аа & 82 & $94 \mathrm{Aa}$ & $88 \mathrm{Aa}$ & $91 \mathrm{~A} \mathrm{~b}$ & 91 \\
\hline Média & 87 & 70 & 81 & & 91 & 89 & 92 & \\
\hline CV (\%) & & & & 3,43 & & & & \\
\hline
\end{tabular}

${ }^{1}$ Letras maiúsculas: comparação entre médias, na mesma linha; letras minúsculas, na mesma coluna $(\mathrm{p}<0,05)$.

contagem, e da BR 16 na contagem final do teste de germinação.

De acordo com as normas de produção de sementes vigentes no Estado do Paraná (Paraná, 1986), a germinação mínima aceitável é de 80\% para as classes certificada e fiscalizada. Portanto, a partir dessa informação é possível inferir, levando em conta os padrões comerciais, que as épocas de semeadura tardias do ano agrícola de 1998/99 foram desfavoráveis para a produção de sementes da maioria dos cultivares avaliados, com exceção do FT-Estrela, nas semeaduras de janeiro e fevereiro, e dos cultivares BRS 133 e BRS 134 na semeadura realizada em fevereiro (Tabela 1B).

Para os testes de classificação de vigor das plântulas e envelhecimento acelerado (Tabela 2), as semeaduras realizadas nas épocas de novembro e fevereiro foram as mais favoráveis à obtenção de sementes de melhor qualidade na região de Maringá-PR, para a maioria dos cultivares, no primeiro ano agrícola (Tabela 2B). No segundo ano, a variação entre as épocas de semeadura foi menos acentuada, não ocorrendo diferenças significativas para a maioria dos cultivares avalia- dos, principalmente no teste de classificação do vigor das plântulas (Tabela 2A). Estes resultados podem ser explicados pela menor incidência de microrganismos em algumas épocas (Figura 2), o que pode ter ocorrido em virtude das condições climáticas mais favoráveis observadas nessas épocas de semeadura (Figura 1). Resultados semelhantes a este foram obtidos em outros trabalhos dessa natureza (Nakagawa et al., 1983; Vieira et al., 1985; Costa et al., 1995). Desta forma, os resultados obtidos nos testes de germinação (primeira contagem e contagem final), classificação do vigor das plântulas e envelhecimento acelerado indicaram a possibilidade de obtenção de sementes com qualidade satisfatória, para os cultivares BRS 133 e FT-Estrela, na semeadura realizada no mês de fevereiro (Tabelas 1 e 2).

Considerando o grau de umidade das sementes antes e após o envelhecimento acelerado observou-se que os tratamentos apresentaram umidade inicial variando de 8,5 a 10,1\% (b.u.) antes da condução do teste e, após o período de exposição ao envelhecimento (48 horas), a umidade das sementes atingiu entre 22,5 e 23,2\%, estando de acordo com os valores 
TABELA 2. Médias estimadas da porcentagem de plântulas normais fortes no teste de classificação do vigor das plântulas (A) e de plântulas normais no teste de envelhecimento acelerado (B) das sementes de cinco cultivares de soja, em três épocas de semeadura e dois anos experimentais (Maringá, PR).

\begin{tabular}{|c|c|c|c|c|c|c|c|c|}
\hline \multirow{3}{*}{ Cultivar } & \multicolumn{3}{|c|}{ Ano agrícola 1998/99 } & \multirow{3}{*}{ Média } & \multirow{2}{*}{\multicolumn{3}{|c|}{$\begin{array}{c}\text { Ano agrícola 1999/00 } \\
\text { Época de semeadura }\end{array}$}} & \multirow{3}{*}{$\begin{array}{c}\text { A } \\
\text { Média }\end{array}$} \\
\hline & \multicolumn{3}{|c|}{ Época de semeadura } & & & & & \\
\hline & $15 / 11$ & $15 / 01$ & $15 / 02$ & & $15 / 11$ & $15 / 01$ & $15 / 02$ & \\
\hline BRS 132 & $87 \mathrm{Aa}^{1}$ & $65 \mathrm{C} \mathrm{b}$ & $72 \mathrm{~B}$ & 75 & $87 \mathrm{Aa}$ & 89Aа & $86 \mathrm{~A} \mathrm{~b}$ & 88 \\
\hline BRS 133 & $82 \mathrm{~A} \mathrm{~b}$ & $76 \mathrm{Ba}$ & $82 \mathrm{Aa}$ & 80 & $90 \mathrm{Aa}$ & 89Аа & $90 \mathrm{Aa}$ & 90 \\
\hline BRS 134 & $88 \mathrm{Aa}$ & $66 \mathrm{C} \mathrm{b}$ & $83 \mathrm{Ba}$ & 79 & $91 \mathrm{Aa}$ & $91 \mathrm{Aa}$ & 93Аа & 92 \\
\hline BR 16 & $85 \mathrm{Aa}$ & 57C C & $78 \mathrm{~B} b$ & 73 & $83 \mathrm{~A} \mathrm{~b}$ & $79 B \mathrm{~b}$ & $85 \mathrm{~A} \mathrm{~b}$ & 82 \\
\hline FT-Estrela & $79 \mathrm{~A} \mathrm{~b}$ & $78 \mathrm{Aa}$ & $82 \mathrm{Aa}$ & 80 & $91 \mathrm{Aa}$ & $85 \mathrm{Aa}$ & 89Аа & 88 \\
\hline Média & 84 & 68 & 79 & & 88 & 87 & 89 & \\
\hline CV (\%) & & & & 3,29 & & & & \\
\hline \multirow{3}{*}{ Cultivar } & \multicolumn{3}{|c|}{ Ano agrícola 1998/99 } & & \multicolumn{3}{|c|}{ Ano agrícola 1999/00 } & $\mathbf{B}$ \\
\hline & \multicolumn{3}{|c|}{ Época de semeadura } & Média & \multicolumn{3}{|c|}{ Época de semeadura } & Média \\
\hline & $15 / 11$ & $15 / 01$ & $15 / 02$ & & $15 / 11$ & $15 / 01$ & $15 / 02$ & \\
\hline BRS 132 & 84Aa & $61 \mathrm{C} \mathrm{b}$ & $70 \mathrm{~B} \mathrm{~b}$ & 72 & 83Аа & 83Аа & 89Аа & 85 \\
\hline BRS 133 & $77 \mathrm{~A} \quad \mathrm{~b}$ & $63 \mathrm{~B} b$ & $80 \mathrm{Aa}$ & 73 & $86 \mathrm{Ba}$ & $79 \mathrm{Ca}$ & $94 \mathrm{Aa}$ & 86 \\
\hline BRS 134 & $84 \mathrm{Aa}$ & $74 \mathrm{Ba}$ & $80 \mathrm{Aa}$ & 79 & $87 \mathrm{Ba}$ & $83 \mathrm{Ba}$ & $94 \mathrm{Aa}$ & 88 \\
\hline BR 16 & $87 \mathrm{Aa}$ & $48 \mathrm{C} \quad \mathrm{c}$ & $80 \mathrm{Ba}$ & 72 & 83Аа & $77 \mathrm{Ba}$ & 88Аа & 83 \\
\hline FT-Estrela & $74 \mathrm{~A} \mathrm{~b}$ & $61 \mathrm{~B} b$ & 79Аа & 71 & $85 \mathrm{Aa}$ & $81 \mathrm{Aa}$ & 89Аа & 85 \\
\hline Média & 81 & 61 & 78 & & 85 & 81 & 91 & \\
\hline CV (\%) & & & & 5,16 & & & & \\
\hline
\end{tabular}

${ }^{1}$ Letras maiúsculas: comparação entre médias, na mesma linha; letras minúsculas, na mesma coluna $(\mathrm{p}<0,05)$.

referenciais citados por Marcos Filho (1999) para essa faixa de umidade inicial.

Segundo Bhéring et al. (1991), em geral, o melhor período para a semeadura da soja visando a produção de sementes com boa qualidade fisiológica na região de Viçosa-MG situou-se entre o final de novembro e início de dezembro, quando a maioria dos genótipos apresentou maior germinação e potencial de vigor. A região de Maringá-PR, por apresentar temperaturas relativamente altas durante a fase da produção da soja, tem sido considerada como medianamente favorável para produção de sementes de soja no Estado do Paraná (Costa et al., 1992). Contudo, os resultados obtidos nesse trabalho indicaram a possibilidade de obtenção de sementes de boa qualidade na semeadura realizada nos meses de novembro e fevereiro.

Os resultados obtidos na avaliação do comprimento das plântulas e da biomassa seca das plântulas de soja estão apresentados na Tabela 3. Foi possível observar que esses testes de vigor baseados no desempenho das plântulas não foram adequados na avaliação do potencial fisiológico das semen- tes produzidas nas diferentes épocas de semeadura, pelo fato dessas avaliações não terem apresentado relação com os testes de germinação e vigor discutidos anteriormente (Tabelas 1 e 2). Nestas avaliações, tanto a medida do comprimento, como a determinação da biomassa seca, por serem medidas de grandeza física (dimensão e massa), independem da subjetividade do analista, o que os torna testes de reprodutibilidade mais fácil. Porém, na soja, existem diferenças de comportamento entre genótipos quanto ao crescimento das plântulas. Desta forma, os resultados devem ser interpretados dentro de cada genótipo conforme sugerido por Nakagawa (1999).

A avaliação visual das sementes (Tabela 4) não apresentou resultados consistentes e precisos para serem comparados com os testes de germinação, de classificação do vigor das plântulas e de envelhecimento acelerado (Tabelas 1 e 2), permitindo inferir que a qualidade das sementes não deve ser caracterizada apenas pela avaliação visual. Entretanto, foi possível verificar que, na época de semeadura preferencial (novembro), foi obtido o melhor resultado para essa característica, concordando com os resultados do teste de germina- 
TABELA 3. Médias estimadas do comprimento das plântulas (A), em centímetros, e da biomassa seca das plântulas (B), em miligrama/plântula, das sementes de cinco cultivares de soja, em três épocas de semeadura e dois anos experimentais (Maringá, PR).

\begin{tabular}{|c|c|c|c|c|c|c|c|c|}
\hline \multirow{3}{*}{ Cultivar } & \multicolumn{3}{|c|}{ Ano agrícola 1998/99 } & \multirow{3}{*}{ Média } & \multirow{2}{*}{\multicolumn{3}{|c|}{$\begin{array}{c}\text { Ano agrícola 1999/00 } \\
\text { Época de semeadura }\end{array}$}} & \multirow{3}{*}{$\begin{array}{c}\text { A } \\
\text { Média }\end{array}$} \\
\hline & \multicolumn{3}{|c|}{ Época de semeadura } & & & & & \\
\hline & $15 / 11$ & $15 / 01$ & $15 / 02$ & & $15 / 11$ & $15 / 01$ & $15 / 02$ & \\
\hline BRS 132 & $33,38 \mathrm{Aa}^{1}$ & $32,77 \mathrm{~A} \quad \mathrm{~b}$ & $31,55 \mathrm{~A} \mathrm{~b}$ & 32,57 & 38,19Аа & $38,44 \mathrm{Aa}$ & $36,86 \mathrm{~A} \mathrm{~b}$ & 37,83 \\
\hline BRS 133 & $32,33 \mathrm{Ba}$ & $34,87 \mathrm{Aa}$ & $33,02 \mathrm{Ba}$ & 33,41 & $37,29 \mathrm{Aa}$ & $39,10 \mathrm{Aa}$ & $38,13 \mathrm{Aa}$ & 38,17 \\
\hline BRS 134 & 31,63Aa & $32,56 \mathrm{~A} \mathrm{~b}$ & 33,07 Aa & 32,42 & 37,91 Aa & $40,20 \mathrm{Aa}$ & $38,80 \mathrm{Aa}$ & 38,97 \\
\hline BR 16 & $31,65 \mathrm{Ba}$ & $33,25 \mathrm{~A} \mathrm{~b}$ & 33,62 Aa & 32,84 & 37,63Аа & 38,92 Aa & 37,72Aa & 38,09 \\
\hline FT-Estrela & $27,27 \mathrm{C} \mathrm{b}$ & $34,02 \mathrm{Aa}$ & $31,35 \mathrm{~B} \quad \mathrm{~b}$ & 30,88 & $35,31 \mathrm{~A} \mathrm{~b}$ & $37,02 \mathrm{~A} b$ & $35,88 \mathrm{~A} \mathrm{~b}$ & 36,07 \\
\hline Média & 31,25 & 33,49 & 32,52 & & 37,27 & 38,74 & 37,48 & \\
\hline CV (\%) & & & & 2,71 & & & & \\
\hline
\end{tabular}

\begin{tabular}{|c|c|c|c|c|c|c|c|c|}
\hline \multirow{3}{*}{ Cultivar } & \multirow{2}{*}{\multicolumn{3}{|c|}{$\begin{array}{c}\text { Ano agrícola 1998/99 } \\
\text { Época de semeadura }\end{array}$}} & \multirow{3}{*}{ Média } & \multirow{2}{*}{\multicolumn{3}{|c|}{$\begin{array}{c}\text { Ano agrícola 1999/00 } \\
\text { Época de semeadura }\end{array}$}} & \multirow{3}{*}{$\begin{array}{c}\text { B } \\
\text { Média }\end{array}$} \\
\hline & & & & & & & & \\
\hline & $15 / 11$ & $15 / 01$ & $15 / 02$ & & $15 / 11$ & $15 / 01$ & $15 / 02$ & \\
\hline BRS 132 & 47,26 & 68,71 & 50,01 & 55,33 & 51,99B b & $57,21 \mathrm{~A} \mathrm{~b}$ & $54,00 \mathrm{Ba}$ & 54,40 \\
\hline BRS 133 & 49,84 & 60,45 & 49,61 & 53,30 & $53,96 \mathrm{~B} \quad \mathrm{~b}$ & $59,19 \mathrm{~A} \mathrm{~b}$ & 57,79Аа & 56,98 \\
\hline BRS 134 & 43,45 & 54,85 & 45,51 & 47,94 & $49,37 \mathrm{~B} \quad \mathrm{~b}$ & $58,72 \mathrm{~A} \quad \mathrm{~b}$ & 55,74Aa & 54,61 \\
\hline BR 16 & 54,58 & 70,16 & 47,30 & 57,35 & $58,79 B$ а & $63,84 \mathrm{Aa}$ & $57,16 \mathrm{Ba}$ & 59,93 \\
\hline FT-Estrela & 43,48 & 62,93 & 49,30 & 51,90 & $50,41 \mathrm{~B} \quad \mathrm{~b}$ & $56,48 \mathrm{~A} \quad \mathrm{~b}$ & 58,11Aa & 55,00 \\
\hline Média & $47,72 \mathrm{~B}$ & $63,42 \mathrm{~A}$ & $48,35 \mathrm{~B}$ & & 52,90 & 59,09 & 56,56 & \\
\hline CV (\%) & & 12,62 & & & & 3,72 & & \\
\hline
\end{tabular}

${ }^{1}$ Letras maiúsculas: comparação entre médias, na mesma linha; letras minúsculas, na mesma coluna $(\mathrm{p}<0,05)$.

ção. De acordo com Zuffo et al. (1987), o teste padrão de germinação, o teste de emergência em areia e o teste de emergência no campo relacionaram-se entre si, enquanto que a avaliação visual não se relacionou com nenhum deles.

A sanidade das sementes, avaliada com base no total de fungos presentes nas sementes dos cinco cultivares de soja, em função das épocas de semeadura, está apresentada na Tabela 5. Observa-se que o retardamento da época de semeadura para o mês de janeiro foi prejudicial à sanidade das sementes de soja produzidas na região de Maringá-PR nos dois anos experimentais. Considerando-se a média obtida para os cinco cultivares avaliados, no ano agrícola de 1999/00, a incidência de patógenos nas sementes foi inferior à verificada no ano anterior, favorecendo a obtenção de sementes de melhor qualidade (Tabelas 1 e 2).

O comportamento observado para essa característica está de acordo com os resultados obtidos na avaliação do potencial fisiológico das sementes (Tabelas 1 e 2), indicando que a semeadura realizada em novembro possibilita não só a ob- tenção de sementes mais vigorosas, como também com menores índices de infecção das sementes por microorganismos patogênicos (Tabela 5). Resultados semelhantes a este foram obtidos por Val et al. (1985).

A análise individualizada dos principais patógenos presentes nas sementes está apresentada na Tabela 6. Esta análise permitiu a obtenção de informações mais detalhadas a respeito da incidência dos principais microrganismos em cada época de semeadura, permitindo realizar inferências mais específicas acerca da sua importância relativa. Os principais gêneros de fungos isolados e identificados nessa avaliação foram os seguintes: Aspergillus spp., Cercospora kikuchii, Colletotrichum dematium, Fusarium semitectum e Phomopsis spp. Das espécies de Aspergillus identificadas predominaram A. flavus e A. niger. Dos microrganismos avaliados, houve predominância dos gêneros Phomopsis spp. e Fusarium semitectum nas três épocas de semeadura do ano agrícola de 1998/99.

No segundo ano agrícola (1999/00), a incidência de 
TABELA 4. Médias estimadas da qualidade visual das sementes de cinco cultivares de soja, em três épocas de semeadura e dois anos experimentais (Maringá, PR).

\begin{tabular}{|c|c|c|c|c|c|c|c|c|c|}
\hline \multirow{3}{*}{ Cultivar } & \multicolumn{3}{|c|}{ Ano agrícola 1998/99 } & \multirow{3}{*}{ Média } & \multirow{2}{*}{\multicolumn{4}{|c|}{$\begin{array}{c}\text { Ano agrícola 1999/00 } \\
\text { Época de semeadura }\end{array}$}} & \multirow{3}{*}{ Média } \\
\hline & \multicolumn{3}{|c|}{ Época de semeadura } & & & & & & \\
\hline & $15 / 11$ & $15 / 01$ & $15 / 02$ & & $15 / 11$ & $15 / 01$ & $15 / 02$ & & \\
\hline BRS 132 & $2,83 \mathrm{Ca}^{1}$ & $3,67 \mathrm{Ba}$ & 4,17 Aa & 3,56 & $2,25 \mathrm{Ba}$ & 4,00Aa & $4,25 \mathrm{Aa}$ & & 3,50 \\
\hline BRS 133 & $2,33 \mathrm{C} \quad \mathrm{b}$ & $3,00 \mathrm{~B} \quad \mathrm{~b}$ & $3,50 \mathrm{~A} \mathrm{~b}$ & 2,94 & $2,00 \mathrm{Ba}$ & 4,17 Aa & $3,92 \mathrm{~A}$ & $\mathrm{~b}$ & 3,36 \\
\hline BRS 134 & $1,33 \mathrm{C}$ & $2,67 \mathrm{~B}$ & $3,17 \mathrm{~A}$ & 2,39 & $1,92 \mathrm{Ba}$ & 3,67 Aa & $3,75 \mathrm{~A}$ & b & 3,11 \\
\hline BR 16 & $2,33 \mathrm{C} \quad \mathrm{b}$ & $3,83 \mathrm{Ba}$ & $4,17 \mathrm{Aa}$ & 3,44 & $2,17 \mathrm{Ba}$ & 3,83Aa & $4,08 \mathrm{Aa}$ & & 3,36 \\
\hline FT-Estrela & $2,58 \mathrm{Ba}$ & $3,17 \mathrm{~A} \quad \mathrm{~b}$ & 3,17A & 2,97 & $2,25 \mathrm{Ba}$ & 3,92 Aa & 4,17 Aa & & 3,45 \\
\hline Média & 2,28 & 3,27 & 3,64 & & 2,12 & 3,92 & 4,63 & & \\
\hline CV (\%) & & & & 6,06 & & & & & \\
\hline
\end{tabular}

${ }^{1}$ Letras maiúsculas: comparação entre médias, na mesma linha; letras minúsculas, na mesma coluna $(\mathrm{p}<0,05)$.

TABELA 5. Médias estimadas da porcentagem total de fungos das sementes de cinco cultivares de soja, em três épocas de semeadura e dois anos experimentais (Maringá, PR).

\begin{tabular}{|c|c|c|c|c|c|c|c|c|}
\hline \multirow{3}{*}{ Cultivar } & \multicolumn{3}{|c|}{ Ano agrícola 1998/99 } & \multirow{3}{*}{ Média } & Ano aq & rícola & $999 / 00$ & \multirow{3}{*}{ Média } \\
\hline & \multicolumn{3}{|c|}{ Época de semeadura } & & \multicolumn{3}{|c|}{ Época de semeadura } & \\
\hline & $15 / 11$ & $15 / 01$ & $15 / 02$ & & $15 / 11$ & $15 / 01$ & $15 / 02$ & \\
\hline BRS 132 & 16,33 & 70,00 & 52,33 & 46,22 & 1,33 & 8,67 & 0,67 & 3,56 \\
\hline BRS 133 & 44,33 & 53,33 & 38,67 & 45,44 & 5,00 & 7,00 & 0,67 & 4,22 \\
\hline BRS 134 & 63,33 & 63,00 & 50,33 & 58,89 & 7,00 & 3,00 & 0,33 & 3,44 \\
\hline BR 16 & 29,00 & 74,33 & 57,33 & 53,55 & 5,00 & 13,00 & 0,00 & 6,00 \\
\hline FT-Estrela & 21,33 & 57,33 & 30,33 & 36,33 & 3,33 & 7,67 & 1,67 & 4,22 \\
\hline Média & $34,86 \mathrm{~B}$ & $63,60 \mathrm{~A}$ & $45,80 \mathrm{~B}$ & & 4,33 & 7,87 & 0,67 & \\
\hline CV (\%) & & 35,19 & & & & 46,44 & & \\
\hline
\end{tabular}

${ }^{1}$ Letras maiúsculas: comparação entre médias, na mesma linha; letras minúsculas, na mesma coluna $(\mathrm{p}<0,05)$.

patógenos nas sementes foi inferior à observada no ano anterior (Tabela 6), favorecendo a obtenção de sementes de melhor potencial fisiológico (Tabelas 1 a 2). As maiores médias de infecção por microrganismos ocorreram na semeadura realizada em 15/01, em que houve predominância de Phomopsis spp., Fusarium semitectum e Colletotrichum dematium, com médias para os cinco cultivares de 4,13, 2,13 e 1,33\%, respectivamente. Os demais patógenos apresentaram índices de infecção reduzidos nas sementes dos cultivares de soja, no decorrer das diferentes épocas de semeadura avaliadas. 
TABELA 6. Incidência de microrganismos nas sementes de cinco cultivares de soja, em três épocas de semeadura e dois anos experimentais (Maringá, PR).

\begin{tabular}{|c|c|c|c|c|c|c|c|c|}
\hline \multicolumn{3}{|c|}{ Tratamentos } & \multicolumn{6}{|c|}{ Microrganismos isolados (\%) } \\
\hline $\begin{array}{c}\text { Ano } \\
\text { agrícola }\end{array}$ & $\begin{array}{c}\text { Época de } \\
\text { semeadura }\end{array}$ & Cultivar & $\begin{array}{c}\text { Aspergillus } \\
\text { spp. }\end{array}$ & $\begin{array}{c}\text { Cercospora } \\
\text { kikuchii }\end{array}$ & $\begin{array}{l}\text { Colletotrichum } \\
\text { dematium }\end{array}$ & $\begin{array}{l}\text { Fusarium } \\
\text { semitectum }\end{array}$ & $\begin{array}{l}\text { Phomopsis } \\
\text { spp. }\end{array}$ & Total \\
\hline \multirow{15}{*}{ 1998/99 } & \multirow{5}{*}{$15 / 11$} & BRS 132 & 0,00 & 0,00 & 0,00 & 0,00 & 16,33 & 16,33 \\
\hline & & BRS 133 & 0,00 & 6,33 & 3,67 & 0,00 & 34,33 & 44,33 \\
\hline & & BRS 134 & 0,00 & 0,00 & 0,00 & 30,00 & 33,33 & 63,33 \\
\hline & & BR 16 & 0,00 & 0,00 & 0,00 & 0,00 & 29,00 & 29,00 \\
\hline & & FT-Estrela & 0,00 & 3,00 & 1,00 & 2,00 & 15,33 & 21,33 \\
\hline & \multirow{5}{*}{$15 / 01$} & BRS 132 & 6,67 & 0,00 & 3,33 & 15,00 & 45,00 & 70,00 \\
\hline & & BRS 133 & 0,00 & 8,33 & 1,67 & 10,00 & 33,33 & 53,33 \\
\hline & & BRS 134 & 2,00 & 5,67 & 2,33 & 10,00 & 43,00 & 63,00 \\
\hline & & BR 16 & 0,00 & 3,00 & 2,00 & 14,33 & 55,00 & 74,33 \\
\hline & & FT-Estrela & 1,33 & 4,33 & 3,33 & 16,67 & 31,67 & 57,33 \\
\hline & \multirow{5}{*}{$15 / 02$} & BRS 132 & 1,00 & 3,00 & 0,33 & 31,67 & 16,33 & 52,33 \\
\hline & & BRS 133 & 4,00 & 5,67 & 1,33 & 16,00 & 11,67 & 38,67 \\
\hline & & BRS 134 & 5,00 & 4,67 & 3,33 & 23,33 & 14,00 & 50,33 \\
\hline & & BR 16 & 4,00 & 6,33 & 0,00 & 34,67 & 12,33 & 57,33 \\
\hline & & FT-Estrela & 3,00 & 2,33 & 0,33 & 11,00 & 13,67 & 30,33 \\
\hline \multirow{15}{*}{$1999 / 00$} & \multirow{5}{*}{$15 / 11$} & BRS 132 & 0,00 & 1,00 & 0,00 & 0,33 & 0,00 & 1,33 \\
\hline & & BRS 133 & 0,00 & 0,00 & 0,00 & 0,00 & 5,00 & 5,00 \\
\hline & & BRS 134 & 0,00 & 0,00 & 0,00 & 0,00 & 7,00 & 7,00 \\
\hline & & BR 16 & 0,00 & 0,00 & 1,33 & 1,67 & 2,00 & 5,00 \\
\hline & & FT-Estrela & 0,00 & 2,33 & 0,00 & 0,00 & 1,00 & 3,33 \\
\hline & \multirow{5}{*}{$15 / 01$} & BRS 132 & 0,00 & 0,00 & 2,67 & 4,33 & 1,67 & 8,67 \\
\hline & & BRS 133 & 0,00 & 0,00 & 1,00 & 2,67 & 3,33 & 7,00 \\
\hline & & BRS 134 & 0,00 & 0,00 & 3,00 & 0,00 & 0,00 & 3,00 \\
\hline & & BR 16 & 0,00 & 0,00 & 0,00 & 0,00 & 13,00 & 13,00 \\
\hline & & FT-Estrela & 1,33 & 0,00 & 0,00 & 3,67 & 2,67 & 7,67 \\
\hline & \multirow{5}{*}{$15 / 02$} & BRS 132 & 0,00 & 0,00 & 0,67 & 0,00 & 0,00 & 0,67 \\
\hline & & BRS 133 & 0,00 & 0,00 & 0,67 & 0,00 & 0,00 & 0,67 \\
\hline & & BRS 134 & 0,00 & 0,00 & 0,33 & 0,33 & 0,00 & 0,33 \\
\hline & & BR 16 & 0,00 & 0,00 & 0,00 & 0,00 & 0,00 & 0,00 \\
\hline & & FT-Estrela & 0,00 & 0,00 & 0,00 & 0,00 & 1,67 & 1,67 \\
\hline
\end{tabular}

\section{CONCLUSÕES}

Os resultados obtidos permitiram concluir que a semeadura no período de safrinha acarreta produção de sementes com potencial fisiológico e sanitário inferior a semeadura realizada em novembro, embora a semeadura realizada em fevereiro tenha proporcionado a obtenção de sementes com qualidade satisfatória. Por outro lado, esse comportamento apresenta diferenças entre os cultivares, em função do atraso na época de semeadura e do ano agrícola avaliado. 


\section{REFERÊNCIAS}

BANZATTO, D.A.; KRONKA, S.N. Experimentação agrícola. 3 ed. Jaboticabal: FUNEP, 1995. 247 p.

BHÉRING, M.C. et al. Influência de épocas de plantio sobre a qualidade fisiológica das sementes de soja (Glycine max (L.) Merrill). Revista Ceres, Viçosa, v.38, n.219, p.409-421, 1991.

BRASIL. Ministério da Agricultura e Reforma Agrária. Regras para análise de sementes. Brasília: DNDV/SNAD/CLAV, 1992. 365p.

COSTA, A.V. et al. Alguns fatores que afetam a qualidade fisiológica da semente de soja. Goiânia: EMGOPA, 1987. 48p. (Documentos, 2).

COSTA, N.P. et al. Zoneamento ecológico do Estado do Paraná para a produção de sementes de cultivares precoces de soja. Londrina: Embrapa-CNPSo, 1992. 28p. (EMBRAPA-CNPSO. Boletim de Pesquisa, 2).

COSTA, N.P. et al. Efeito da época de semeadura sobre a qualidade fisiológica de sementes de soja no Estado do Mato Grosso. Revista Brasileira de Sementes, Brasília, v.17, n.1, p.107-112, 1995.

DELOUCHE, J.C. Physiological changes during storage that affect soybean seed quality. In: SINCLAIR, J.B.; JACKOBS, J.A. (Ed.). Soybean seed quality and stand establishment. s.l.: Intsoy, 1982. p.57-66. (Intsoy, 22).

DHINGRA, O.D.; ACUÑA, R.S. Patologia de sementes de soja. Viçosa: Editora UFV, 1997. 119p.

EMBRAPA SOJA. Recomendações técnicas para a cultura da soja no Paraná 1999/2000. Londrina: Embrapa Soja, 1999. 236p. (Embrapa Soja. Documentos, 131).

FEHR, W.R. et al. Stage of development description for soybean, Glycine max (L.) Merrill. Crop Science, Madison, v.11, n.6, p.929931, 1971.

GOULART, A.C.P. Fungos em sementes de soja: detecção e importância. Dourados: EMBRAPA-CPAO, 1997. 58p. (EMBRAPA-CPAO. Documentos, 11).

GREEN, D.E. Effect of planting date and maturity date on soybean seed quality. Agronomy Journal, Madison, v.57, n.2, p.165-168, 1965.

HARRINGTON, J.F. Biochemical basis of seed longevity. Seed Science and Technology, Zurich, v. 1, p.453-461, 1973.

HENNING, A.A. Patologia de sementes. Londrina: EMBRAPACNPSo, 1994. 43p. (EMBRAPA-CNPSo Documentos, 90).

JACINTO, J.B.C.; CARVALHO, N.M. Maturação de sementes de soja (Glycine max (L.) Merrill). Científica, Jaboticabal, v.1, n.1, p.81-88, 1974.

MARCOS FILHO, J. Maturação de sementes de soja da cultivar Santa Rosa. Revista Brasileira de Sementes, Brasília, v.1, n.2, p.4963, 1979.

MARCOS FILHO, J. Produção de sementes de soja. Campinas: Fundação Cargill, 1986. 86p.

MARCOS FILHO, J. Teste de envelhecimento acelerado. In:
KRZYZANOWSKI, F.C.; VIEIRA, R.D.; FRANÇA NETO, J.B. (Ed.). Vigor de sementes: conceitos e testes. Londrina: ABRATES, 1999. 3-21p.

MONDRAGON, R.L.; POTTS, H.C. Field deterioration of soybean as affected by environment. Proceedings of Association of Official Seed Analysts, Lincoln, v.64, p.63-71, 1974.

NAKAGAWA, J.; ROSOLEM, C.A.; MACHADO, J.R. Épocas de semeadura da soja. I. Efeitos na produção de grãos e nos componentes da produção. Pesquisa Agropecuária Brasileira, Brasília, v.18, n.11, p.1187-1198, 1983.

NAKAGAWA, J. Testes de vigor baseados no desempenho das plântulas. In: KRZYZANOWSKI, F.C.; VIEIRA, R.D.; FRANÇA NETO, J.B. (Ed.). Vigor de sementes: conceitos e testes. Londrina: ABRATES, 1999. 2-21p.

PARANÁ. Secretaria de Estado da Agricultura. Normas de produção de sementes, básica, registrada, certificada e fiscalizada. Curitiba: Empresa Paranaense de Classificação de Produtos, 1986.

POPINIGIS, F. Fisiologia da semente. 2.ed. Brasília: AGIPLAN, 1985. 289p.

ROBERTS, E.H. Loss of viability and crop yields. In: ROBERTS, E.H. (Ed.). Viability of Seeds. London: Chapman and Hall, 1974. p.307-320.

ROCHA, V.S. et al. A qualidade da semente de soja. Viçosa: UFV, 1984. 76p. (Boletim, 188).

SCOTT, A.; KNOTT, M. Cluster-analysis method for grouping means in analysis of variance. Biometrics, Washington, v.30, n.3, p.507-512, 1974.

TEKRONY, D.M.; EGLY, D.B.; PHILLIPS, A.D. Effects of field weathering on the viability and on vigor of soybean seed. Agronomy Journal, Madison, v.72, n.5, p.749-753, 1980.

TEKRONY, D.M. Effect of date of harvest maturity on soybean seed quality and Phomopsis sp. seed infection. Crop Science, Madison, v.24, n.1, p.189-193, 1984.

VAL, W.M.C.; GAUDENCIO, C.A.; GARCIA, A. Ensaio sobre época de plantio. In: EMBRAPA.Centro Nacional de Pesquisa de Soja. Resultados da pesquisa de soja, 1984/85. Londrina: EMBRAPA-CNPSo, 1985. p.393-396.

VIEIRA, L.R.D. et al. Estudo da qualidade fisiológica de semente de soja (Glycine max (L.) Merrill) cultivar UFV-1 em quinze épocas de colheita. In: SEMINÁRIO NACIONAL DE PESQUISA DE SOJA, 2., Brasília, 1981. Anais... Londrina, EMBRAPA-CNPSo, v.1., 1982. p.633-644.

VIEIRA, S.A. et al. Épocas de semeadura e espaçamento sobre algumas características agronômicas da soja no Planalto RioGrandense. Pesquisa Agropecuária Brasileira, Brasília, v.20, n.2, p.25-226, 1985.

ZUFFO, N.L. et al. Influência da época de semeadura na qualidade de sementes de soja produzidas no Mato Grosso do Sul e correlações entre os métodos de avaliação utilizados. Revista Ceres, Viçosa, v.34, n.195, p.474-487, 1987. 